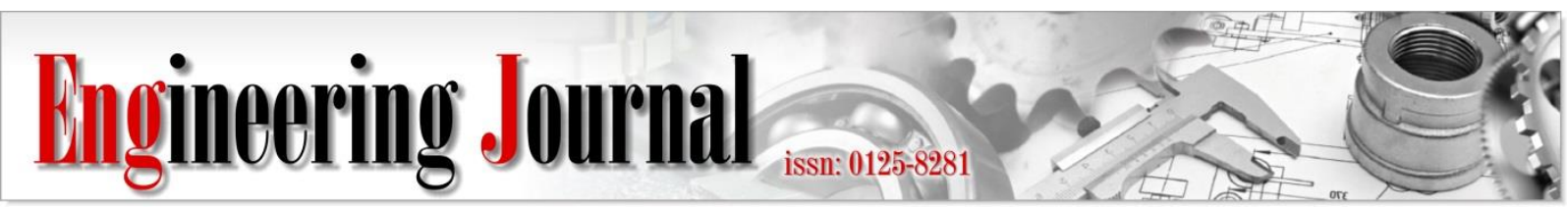

Article

\title{
The Analysis of Essential Factors Responsible for Loss of Labour Productivity in Building Construction Projects in India
}

\author{
Dasari Karthik* and C. B. K. Rao \\ Department of Civil Engineering, National Institute of Technology Warangal, Warangal, India \\ *E-mail: kdcivil13@gmail.com (Corresponding author)
}

\begin{abstract}
.
The purpose of this paper is to find the essential factors influencing the loss of labour productivity (LP) in construction in India and substantiate these factors with naturalistic observation method in a building construction project. From the past studies, factors influencing the LP are specifically selected for the survey and statistically analyzed to form into defined group of factors. The influence of these factors is then correlated to the field level LP. For this, a case study is conducted using TMS technique to inspect factors influencing LP in an ongoing multi storied residential building construction site in Telangana State, India. The LP factors identified by survey analysis are quantitatively validated with the field study. It is noted that work characteristics, organizational characteristics, assured and safety work and workers management were responsible for 15\% loss of LP in the field. Of these, major loss of about $11 \%$ is shown by work characteristics factors such as material delay and tools delay. This method can be utilized by construction personnel to measure the loss of LP with the data available from survey methods and also assists the construction personnel in making timely decisions towards the improvement of LP for various activities on the construction project sites.
\end{abstract}

Keywords: Labour productivity, construction productivity, activity, task, work measurement, time and motion study, construction industry.

ENGINEERING JOURNAL Volume 23 Issue 2

Received 13 August 2018

Accepted 11 December 2018

Published 31 March 2019

Online at http://www.engj.org/

DOI:10.4186/ej.2019.23.2.55 


\section{Introduction}

Construction Industry (CI) is labour-intensive and greatly depends on the efficiency of labour force. Labour Productivity (LP) is the most important aspect that influences the performance of any construction firm [1]. The LP problems are usually associated with the performance of labour force involved with the various tasks in the construction activities. The performance of labour is primly influenced by the factors such as time, cost, and quality of the construction projects [2]. A precise assessment of factors influencing the LP will enable in properly allocating limited resources, provide workers with well support or development towards LP. Assessment of labour issues on construction site considering the influence of crucial LP factors will assist the construction engineers, supervisors and managers in making timely decisions in construction projects.

CI normally defines productivity as effectiveness of labour employed with respect to the management skills, workers materials, working area, tools and equipment or to produce a finished product of construction project at the lowest viable cost [3]. Construction productivity enables the industry to maintain satisfied client, attract investment, remain feasible and contribute to the economic growth and well-being of the country [4]. In today's era, optimized LP is most important aspect for any construction organization. Assessment of labour oriented works in the construction projects is important part of management process [5]. As most of the construction activities are labour intensive, LP is measured at activity level, which measures the input as labour time and the output as installed quantities for the respective time consumed [6]. Thirty to fifty percentage of the overall construction project's cost is contributed to labour and is observed as a true reflection of the financial success of the construction projects [7, 8, 9]. It can also be said that labour output is the only productive means in the construction process, hence construction productivity is mostly reliant on labour performance. While the low productive worker practices presence is not challenged, the causes of low labour performances at site level have not been focused.

The present paper aids in understanding the importance of assessing LP factors with the utilization of data resulted from the questionnaire survey methods and assess the task level LP in the construction projects in India. The objective of the study is focused on to how the heuristic data from questionnaire surveys can be utilized to find the essential factors responsible for the loss of LP in construction project sites. Therefore, a case study on brick layers in a residential apartment building construction site in Telangana State (TS) in India is conducted in which various productive and non-productive tasks of the labour work process are observed using Time and Motion Studies (TMS) technique. The non-productive tasks evaluated on construction site are correlated to the factors influencing the LP from the survey method.

\section{Literature Review}

Several factors influencing the LP in CI have been identified in the earlier studies. LP factors from the most cited international research papers have been identified and considered for the present study. A survey was conducted by Kadir et.al., and collected information for the factors affecting LP for Malaysian residential construction projects in which respondents were requested to specify how important each item in a list of total 50 project specific factors [10]. In this study, material shortage was found to be the important and most frequent factor with highest severity index among all factors. The analysis of factor affecting LP in Trinidad and Tobago, which contained ranking of forty-two predefined factors that are distributed into four categories such as management, technological, human/labour and external factors. The relative importance of indices was resolved and these factors were ranked. Respondents were requested to give their score to all factors using an effect level ranging from 1 to 4 where 1 represents the least effect and 4 represents the most effect on LP [11]. In the same manner, a survey was conducted in Oman comprising of thirty-three LP factors to identify and rank their importance [12]. The probabilistic sampling method was used in order to achieve the statistically representative sample of the population, and the data recorded were analyzed by Relative Importance Index (RII) technique in Oman, Trinidad and Tobago [11, 12]. Mahamid (2013) analyzed thirtyone factors in five groups affecting the LP in building construction in Palestine from contactor's perspective through the structured questionnaire survey [13]. Naoum and Hackman, (1996) conducted a questionnaire survey to find the significant differences in opinions between office level and site level on factors that influencing the construction productivity [14]. Another survey was conducted with construction personnel by Hanna and Heale to measure the opinion on the construction field, precisely the data about the factors that mainly affect construction productivity. From this analysis, a set of complete factors are recognized and categorized into six groups such as contract work environment, planning, site level management, working 
conditions, working hours, and motivation [15]. In this research, labour skill, communication, timeliness and crew supplies were found major factors affecting the construction productivity.

All the above studies were qualitatively validated the LP factors and no attempt is made towards the quantitative validation. There is a need to focus on to what extent these heuristic data can be validated with the correlation of LP measurement on construction project sites. This approach could aid in considering the essential factors responsible for loss of LP in productivity estimates of the construction projects. LP factors were not self-governing and all of them cannot be controlled as the above studies were dealt only with severity of the factors towards the loss of LP. Besides finding the severity of LP factors, measurement of LP with the influence of these factors needs focus which the present study is intended to do. Three models were recognized by H.R. Thomas for measuring LP are economic models, project related model and activity model and LP is defined as activity output per labour hour by utilizing the activity model [16]. Sing et.al., utilized multiplier model to forecast the manpower demand in construction activities [17]. Wong et.al., used time series model as forecasting technique to predict construction labour requirement [18]. Jokkaw et.al., used virtual reality models to assess the performance of the workers by measuring their feelings against safety in high rise building construction projects [19]. Management of construction firms concerning towards the safety of workers increases the LP on project sites. Activity analysis was used to assess the LP on semi-highrise building projects in Pakistan [20]. Such models focusing on activities in the construction field aimed towards the measurement of LP in construction projects.

As the present study is taken up to substantiate the surveyed data into the field level LP in construction projects, LP measurement at task level is required. So, the measurement of LP is carried out by using work measurement techniques on the masonry construction activity. The methods and utilization of work measurement techniques are explained in the below section (2.1). Therefore, the measurement of loss of LP with the correlation of heuristic data and work measurement techniques will become a great tool in developing the LP in the construction projects. This approach can enhance the performance of construction companies in developing countries like India.

\subsection{Work Measurement Techniques}

Assessment of LP on crew or at an individual worker in construction site is to be carried out by the application of work measurement techniques [21]. Work measurement techniques such as activity sampling and time and motion study is used for calculating task level LP on construction site. Activity sampling is a method in which observations are taken at specified intervals and are not continuous which has been successfully utilized for calculating the labour output in the past [22]. These observations constitute to the sampling of a construction activity. Sampling for an activity needs to be collected in two categories namely working and non-working time. Working and non-working time of labour on construction site states the productive and non-productive work tasks in the construction projects.

TMS began in the 1880s by Frederick W. Taylor, who is regarded as the "father of scientific management." This approach has been successfully applied to factories, hospitals, department stores, housework, banks, cafeteria work, libraries, music, and applied for many other human performance activities. Hence an effort has been established in this study for implementing this concept to evaluate LP on construction site. TMS is a work measurement technique for recording the time spent on performing a certain specific task or its elements carried out under specified conditions. Task categories are derived from activity sampling method. TMS is a direct and continuous observation of a task duration, using a timekeeping device (e.g., decimal minute stopwatch, computer-assisted electronic stopwatch, and videotape camera) to record the time taken to accomplish a task. TMS technique is a core set of tools which are used by the managers in the industrial sector to enhance the performance or the operational efficiency. This is done by breaking down the work into simpler units and setting the execution benchmarks. Most of the past studies did not try to inspect the influence of LP factors at activity/task level construction which can provide considerable decision making towards improving LP. TMS is a labor-intensive method of collecting the field data [23]. TMS deals with the methodical approach of desirable work methods, with the purpose of the time necessary for the use of worker to perform the task as specified [24]. TMS can be used to determine the standard time required for manpower in performing the various construction activities [25]. 


\section{Work Methodology}

The present study methodology initially aims to check the reliability of factors influencing the LP in CI in India by organizing them into certain groups. This survey method is based on literature review and the main tool of collecting data from construction personnel is a structured questionnaire survey. The factors influencing LP were evaluated by RII and factor analysis. Factor analysis is carried out using Statistical Package for Social Sciences (SPSS) and new group of factors were derived based on the analysis of survey responses. Reliability of the responses for the factors that formed in newly derived groups is checked using cronbach's alpha method. A case study on twenty-four mason-helper combination of workers is conducted to collect their task level productivity from the construction site using TMS technique. Percentage of time spent on working and non-working tasks with respect to the labour output for the brick wall construction activity is observed. Percentage of various task motions involved in both working and non-working time consumed is calculated. Since the influence of factors from responses majorly related to the non-productive time, time consumed in non-working time task motions (non-productive work) are recorded. These nonworking task motions are then correlated to certain group of factors that are affecting the LP. Thus, the crucial factors influencing the LP is inspected for a construction activity on site which in turn can be useful for both assessing and improving the task level LP in construction projects.

\section{Data Collection}

\subsection{Survey Method}

The purpose of the survey is to analyze the perceptions of construction personnel on the severity of the factors that are responsible for loss of LP at various levels in the construction firms. A detailed questionnaire is prepared to evaluate the factors affecting LP which are adopted from the past studies mentioned in the literature review. The format is divided into two sections. One section contains the general information of respondent and the other Section includes the various factors affecting LP consisting 38 factors under different groups that adversely affect the LP. These factors are then categorized into eight groups: work force, management team, motivation, work condition, material and equipment, work supervision, safety and others. Each of these groups with various factors influencing LP are listed in Table 1.

Total 120 respondents involved in various building construction projects are contacted in TS region and invited to take part in the study through electronic mails. The survey was conducted in the month of March 2017. The respondents are selected such that they should possess experience of at least one complete building construction project or minimum of 5 years in India. Forty-four $(36 \%)$ responses i.e., one from each firm/organization/institute were responded in total. Respondents include 11\% academicians (third-party consultants from educational institutes) and the rest $89 \%$ included construction managers/site engineers from private, government, and multinational construction companies operating in TS region (see Fig. 1). Though the respondents are presently working in TS region, many of their past experience included in different parts of India. Therefore, the results of the survey received from the respondents were adequate to identify the influence of LP factors in building construction projects in India.

Respondents were asked to rate LP factors listed in Table 1, taking various parameters into account such as time, cost, and quality based on their own experiences. For this study, likert scale is used to evaluate the individual's performance or opinion of the given queries. In this study, respondents were asked to rate the factors influencing LP on a scale from "1," very low; "2," low; "3," moderate; "4," high to " 5 ," very high. After the survey data is collected, a technical statistical analysis of factors influencing LP is evaluated by using SPSS. A five-point likert scale results showed a mean of 3.64. 
Table 1. Factors influencing LP adopted for the present study from the literature $[10,11,12,13,14,15]$.

\begin{tabular}{cccl}
\hline S.No & LP Groups & Nos & \multicolumn{1}{c}{ Description of Factors } \\
\hline 1 & Work force & 6 & $\begin{array}{l}\text { Lack of skill and experience of workers, lack of empowerment } \\
\text { (resources and training), high workforce absenteeism, high workforce } \\
\text { turnover, low labour morale/ commitment, poor relation among } \\
\text { workers. }\end{array}$ \\
\hline 2 & $\begin{array}{c}\text { Management } \\
\text { team }\end{array}$ & 4 & $\begin{array}{l}\text { Bad leadership skill, poor relation between workers and } \\
\text { superintendent, lack of labour surveillance, lack of periodic meeting } \\
\text { with labour. }\end{array}$ \\
\hline 3 & Motivation & 4 & $\begin{array}{l}\text { Low amount of pay, little or no financial rewards, lack of labour } \\
\text { recognition program, payment delay. }\end{array}$ \\
\hline 4 & Work condition & 6 & $\begin{array}{l}\text { Working 7 days per week, frequency of overtime, poor work planning, } \\
\text { unrealistic scheduling, labour interface and congestion, design } \\
\text { complexity. }\end{array}$ \\
\hline 5 & Material & 4 & $\begin{array}{l}\text { Material shortages, unsuitable material locations, wquipment and tools } \\
\text { shortages, poor condition of tools and equipment. }\end{array}$ \\
\hline 6 & Work & 5 & $\begin{array}{l}\text { Poor or no supervision method, incompetent supervisors, } \\
\text { ancomplete/ revise drawings, inspection delay, variations/ change } \\
\text { orders during execution. }\end{array}$ \\
\hline 7 & Safety & 4 & $\begin{array}{l}\text { Accidents, unsafe working conditions, inadequate safety plan, working } \\
\text { at heights. }\end{array}$ \\
\hline 8 & Others & 5 & $\begin{array}{l}\text { Rework, method of construction, use of information and } \\
\text { communication technologies, weather conditions and effectiveness of } \\
\text { management system. }\end{array}$ \\
\hline
\end{tabular}

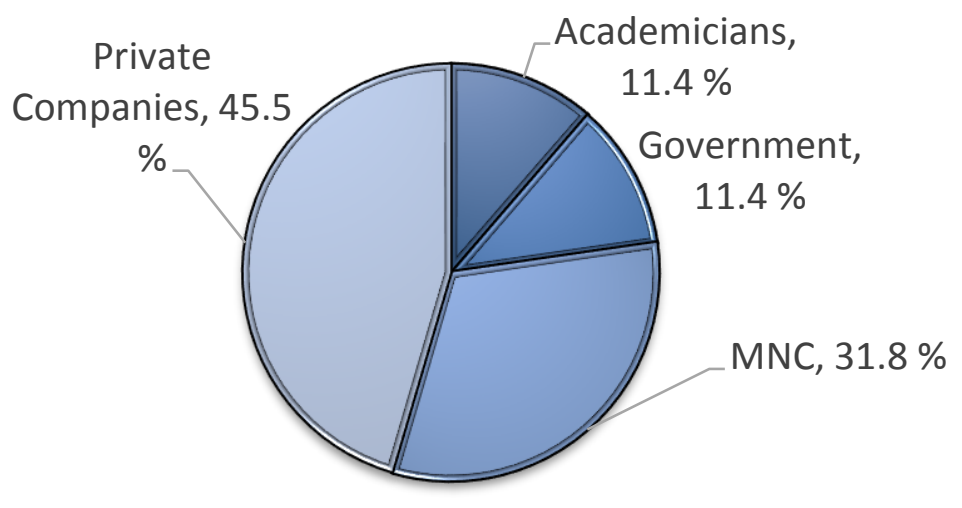

Fig. 1. Percentage of respondents from various construction organizations in the questionnaire survey.

\subsection{Field Method}

A residential apartment construction site is selected for carrying out the investigation on factors influencing LP. Construction of wall using AAC (Autoclaved aerated concrete) blocks is the construction activity chosen for the field study. The activity chosen for the study involves 22 workers (13 masons \& 9 helpers) on the construction site. From the method of activity sampling, various task motions are observed under working and non-working time. These task motions are carried out by workers repetitively that are derived from the preliminary field study. Working and non-working time for labour in carrying out particular task motions for construction of brick wall activity are taken as productive and non-productive working task motions respectively. Various task motions observed under productive and non-productive work is explained below. 
4.2.1. Productive Work: Activity tasks of brick wall construction such as brick laying, aligning, levelling, brick line marking, groove filling and finishing are direct useful tasks required. Supporting tasks such as joinery installation, brick slicing and scaffold installation (working at heights) also falls under productive work as working time of these tasks are necessary in completing the particular activity.

4.2.2. Non-productive work: This is where workers involve in certain actions that are undesirable during the work. These are considered to be delay tasks and are categorized in to two types are 1) supplies delay such as waiting for material handlers, moving away from work area to get tools and human delay like taking help form co-workers, performing repetition due to lower skill, waiting for supervisor to get instructions. 2) Other nonworking tasks include delays that must be avoided completely such as needless moving around, personal mobile conversations, unnecessary chatting with another worker, etc. The level of detail will vary from the overall objectives of activity sampling, the mode of work environment, and the sampling strategy.

Table 2. Classification of various tasks involved in the activity of a wall construction.

\begin{tabular}{|l|l|l|l|}
\hline Category & \multicolumn{2}{|l|}{ Sub-Tasks } & Code \\
\hline \multirow{4}{*}{ Productive Work } & \multirow{3}{*}{ Direct work } & Brick laying & BL \\
\cline { 3 - 4 } & & Aligning / levelling & AL \\
\cline { 3 - 4 } & \multirow{3}{*}{ Supporting work } & Finishing & FIN \\
\cline { 3 - 4 } & & Joinery installation & JI \\
\cline { 3 - 4 } & & Srick slicing & SS \\
\hline \multirow{4}{*}{ Non-Productd installation } & SI \\
\hline \multirow{3}{*}{ Supplies delay } & Material delay & MD \\
\cline { 3 - 4 } & & Tool delay & TD \\
\cline { 3 - 4 } & \multirow{3}{*}{ Human delay } & Supervision delay & SD \\
\cline { 3 - 4 } & & Low skill delay & LSD \\
\cline { 3 - 4 } & & Unwanted conversations & UC \\
\cline { 3 - 4 } & & Miscellaneous & MISC \\
\hline
\end{tabular}

Various task motions categorized under productive and non-productive works that observed in the present study are listed in the above Table 2 .

\section{Analysis and Results}

\subsection{Reliability Analysis}

Reliability analysis is carried out by using Cronbach's alpha method. This method of analysis evaluates core consistency depending on the average correlation amongst the data that is identically computed. Both Splithalf method and item-total correlation is combined in this analysis, and computes the mean value of the reliability from the split-half method for all the data of the concept. From this method, the reliability of the factors influencing LP in executing certain construction activity both at the group and individual level can be calculated as follows:

$$
\alpha=\frac{\mathrm{n}}{\mathrm{n}-1}\left(1-\frac{\sum \sigma_{\mathrm{i}}^{2}}{\sigma_{\mathrm{i}}^{2}}\right)
$$

where $\mathrm{n}=$ number of items, $\sigma_{i}^{2}=$ variance of sum of all scores; $\sum \sigma_{i}^{2}=$ sum of st.dev. of all items.

In generally, Cronbach's alpha value of 0.7 is acceptable for reliability and it could reduce to 0.6 in investigative studies [26]. The analysis of thirty-eight factors at the individual level showed the value of 0.937 which authenticates the reliability of the analysed model that is used in the present work. 


\subsection{Relative Important Index (RII)}

RII is a technique used for ranking of factors from the survey given by various respondents. The RII can be calculated using the following equation

$$
\mathrm{RII}=\frac{\sum_{\mathrm{i}=1}^{\mathrm{n}}\left(\mathrm{w}_{\mathrm{i}} \mathrm{x}_{\mathrm{i}}\right)}{\mathrm{AN}}
$$

where ' $w$ ' is the weight assigned by respondent (1 to 5);

$\mathrm{x}$ ' is frequency of each weightage;

$\mathrm{A}$ is the highest weight; and

$\mathrm{N}$ is the no of respondents participated in the survey.

Based on the responses from the survey conducted, the factors having RII value more than 0.7 is considered. Higher the RII value, the more important was the influence of factors [27]. So, twenty-eight factors as shown in Table 3 are now taken for the further analysis.

Table 3. Relative Important Indices for factors influencing LP.

\begin{tabular}{|c|c|c|c|c|c|c|c|c|}
\hline \multirow[t]{2}{*}{$\begin{array}{c}\text { S. } \\
\text { No }\end{array}$} & $w_{i}$ & 1 & 2 & 3 & 4 & 5 & \multirow[t]{2}{*}{$\begin{array}{c}\Sigma \text { wi } \\
\text { xi }\end{array}$} & \multirow[t]{2}{*}{ RII } \\
\hline & LP Factors & \multicolumn{5}{|c|}{$x_{i}$} & & \\
\hline 1 & Unsafe working conditions & 2 & 2 & 4 & 20 & 16 & 178 & 0.809 \\
\hline 2 & Poor work planning & 1 & 1 & 7 & 25 & 10 & 174 & 0.791 \\
\hline 3 & Unrealistic scheduling & 1 & 4 & 4 & 22 & 13 & 174 & 0.791 \\
\hline 4 & Little or no financial rewards & 1 & 3 & 9 & 18 & 13 & 171 & 0.777 \\
\hline 5 & Material shortages & 2 & 3 & 6 & 20 & 13 & 171 & 0.777 \\
\hline 6 & Payment delay & 2 & 3 & 6 & 21 & 12 & 170 & 0.773 \\
\hline 7 & Working at heights & 2 & 1 & 12 & 17 & 12 & 168 & 0.764 \\
\hline 8 & Weather conditions & 0 & 4 & 10 & 20 & 10 & 168 & 0.764 \\
\hline 9 & Lack of skill and experience of worker & 0 & 2 & 13 & 21 & 8 & 167 & 0.759 \\
\hline 10 & Poor or no supervision method & 2 & 3 & 10 & 16 & 13 & 167 & 0.759 \\
\hline 11 & Incompetent supervisors & 0 & 2 & 11 & 25 & 6 & 167 & 0.759 \\
\hline 12 & Accidents & 2 & 5 & 6 & 18 & 13 & 167 & 0.759 \\
\hline 13 & Poor relation $\mathrm{b} / \mathrm{w}$ labour and superintends & 1 & 3 & 10 & 21 & 9 & 166 & 0.755 \\
\hline 14 & Poor condition of equipment and tools & 3 & 3 & 9 & 16 & 13 & 165 & 0.750 \\
\hline 15 & Bad leadership skill & 1 & 5 & 5 & 27 & 6 & 165 & 0.750 \\
\hline 16 & Working 7 days per week & 4 & 3 & 10 & 12 & 15 & 163 & 0.741 \\
\hline 17 & Equipment and tools shortages & 1 & 5 & 6 & 26 & 6 & 163 & 0.741 \\
\hline 18 & Low labour morale/commitment & 1 & 5 & 10 & 19 & 9 & 162 & 0.736 \\
\hline 19 & Rework & 2 & 2 & 10 & 24 & 6 & 162 & 0.736 \\
\hline 20 & Lack of empowerment & 0 & 3 & 16 & 18 & 7 & 161 & 0.732 \\
\hline 21 & Change order during execution & 1 & 5 & 8 & 24 & 6 & 161 & 0.732 \\
\hline 22 & Low amount of pay & 2 & 5 & 11 & 15 & 11 & 160 & 0.727 \\
\hline 23 & High Workforce Absenteeism & 2 & 4 & 12 & 17 & 9 & 159 & 0.723 \\
\hline 24 & Lack of labour surveillance & 2 & 3 & 12 & 22 & 5 & 157 & 0.714 \\
\hline 25 & Inadequate safety plan & 2 & 4 & 11 & 21 & 6 & 157 & 0.714 \\
\hline 26 & Frequency of Working Overtime & 2 & 3 & 13 & 21 & 5 & 156 & 0.709 \\
\hline 27 & Effectiveness of Management System & 1 & 3 & 18 & 15 & 7 & 156 & 0.709 \\
\hline 28 & Method of Construction & 1 & 4 & 16 & 18 & 5 & 154 & 0.700 \\
\hline
\end{tabular}

\subsection{Factor Analysis}

This method is a statistical analysis which commonly describes the basic dimensions that comprise of factors by analyzing the correlation amongst the factors. From this statistical method adopted, factor analysis results in an un-rotated component factor matrix. This displays the data in a reduced form but does not explains the extent of which a factor is related to the particular group of factors. Consequently, the resulting group of 
factors are rotated to obtain the component structure containing group of factors and is defined as orthogonal factor rotation analysis. In the present study, factor analysis is implemented to prove the factors that are grouped were statistically significant or not. Total twenty-eight factors were selected that are statistically related with the LP resulted from the RII method of analysis. All these twenty-eight factors are analysed in factor analysis using SPSS. From the factor analysis, percentage of variance and the cumulative percentage of factors are derived (see Table 4). The eigenvalue as shown in Table 4 is an index that signifies the explanatory power of the corresponding factor normally obtained from the factors with value of one or more. Total factors are reduced to eight components with value greater than one are shown in Table 4. These eight components that are reduced constitutes to $75 \%$ of total twenty-eight factors. Therefore, the eight components resulted from the factor analysis will form new group of factors which defines the influence of LP from the questionnaire analysis. Rotation sums of squared loadings is carried out in the factor analysis which defines the accurate component structure of LP factors. Total rotation sums of squared loadings among the eight components are considered.

Table 4. Total variance of the factors influencing LP from factor analysis.

\begin{tabular}{|c|c|c|c|c|c|c|}
\hline \multicolumn{7}{|c|}{ Total Variance } \\
\hline \multirow{3}{*}{ Components } & \multicolumn{2}{|c|}{ Initial Eigenvalues (Loadings) } & \multicolumn{3}{c|}{ Rotation Sums of Squared Loadings } \\
\cline { 2 - 7 } & Total & $\begin{array}{c}\text { Percentage of } \\
\text { Variance }\end{array}$ & $\begin{array}{c}\text { Cumulative } \\
\text { Percentage }\end{array}$ & Total & $\begin{array}{c}\text { Percentage of } \\
\text { Variance }\end{array}$ & $\begin{array}{c}\text { Cumulative } \\
\text { Percentage }\end{array}$ \\
\hline 1 & 9.666 & 34.521 & 34.521 & 3.509 & 12.532 & 12.532 \\
\hline 2 & 2.410 & 8.605 & 43.126 & 3.153 & 11.260 & 23.792 \\
\hline 3 & 2.204 & 7.872 & 50.999 & 3.092 & 11.044 & 34.836 \\
\hline 4 & 1.656 & 5.914 & 56.913 & 2.928 & 10.457 & 45.293 \\
\hline 5 & 1.588 & 5.673 & 62.586 & 2.555 & 9.126 & 54.419 \\
\hline 6 & 1.415 & 5.052 & 67.638 & 2.247 & 8.024 & 62.444 \\
\hline 7 & 1.241 & 4.432 & 72.070 & 2.027 & 7.241 & 75.997 \\
\hline 8 & 1.100 & 3.927 & 75.997 & 1.767 & 6.312 & \\
\hline 10 & .825 & 2.945 & 82.172 & & & \\
\hline 11 & .777 & 2.776 & 84.948 & & & \\
\hline 12 & .633 & 2.260 & 87.209 & & & \\
\hline 13 & .510 & 1.821 & 89.029 & & & \\
\hline 14 & .458 & 1.635 & 90.664 & & & \\
\hline 15 & .436 & 1.556 & 92.220 & & & \\
\hline 16 & .406 & 1.452 & 93.672 & & & \\
\hline 17 & .367 & 1.310 & 94.982 & & & \\
\hline 18 & .261 & .931 & 95.912 & & & \\
\hline 19 & .233 & .832 & 96.744 & & & \\
\hline 20 & .227 & .812 & 97.557 & & & \\
\hline 21 & .153 & .547 & 98.103 & & & \\
\hline 22 & .134 & .478 & 98.581 & & & \\
\hline 23 & .112 & .401 & 98.982 & & & \\
\hline 24 & .091 & .324 & 99.306 & & & \\
\hline 25 & .069 & .246 & 99.552 & & & \\
\hline 26 & .058 & .209 & 99.761 & & & \\
\hline 27 & .037 & .134 & 99.894 & & & \\
\hline 28 & .030 & .106 & 100.000 & & & \\
\hline
\end{tabular}

To classify these eight components, an orthogonal factor rotation analysis is processed and the rotated component matrix is analyzed in SPSS (see Table 5). The corresponding factors of components in detail are listed (see Table 6). Thus, eight group of factors were reorganized newly by naming them as per LP factors contained. Cronbach's alpha coefficient is analysed and for newly formed group of factors and verified the factors in each reorganized group are internally consistent (see Table 7). 
Table 5. Rotated component matrix.

\begin{tabular}{|c|c|c|c|c|c|c|c|c|}
\hline \multirow[b]{2}{*}{ LP Factors } & \multicolumn{8}{|c|}{ Component (Group of Factors) } \\
\hline & 1 & 2 & 3 & 4 & 5 & 6 & 7 & 8 \\
\hline Poor condition of equipment and tools & 0.805 & .060 & 287 & 184 & -.021 & .046 & .064 & 160 \\
\hline Bad leadership skill & 0.600 & .063 & 158 & .212 & .291 & .047 & .415 & .084 \\
\hline Rework & 0.583 & .432 & .029 & .074 & .131 & .440 & .213 & -.034 \\
\hline Poor work planning & 0.516 & -.028 & .091 & .255 & .300 & .252 & .019 & .261 \\
\hline Method of construction & -.021 & 0.873 & .047 & .140 & -.030 & .027 & -.038 & .017 \\
\hline Equipment and tools shortages & .493 & 0.715 & -.001 & -.008 & .088 & -.085 & -.079 & .320 \\
\hline Effectiveness of Management system & .072 & 0.616 & .246 & .285 & .229 & .210 & -.103 & -.188 \\
\hline Material shortages & .360 & 0.545 & .241 & -.101 & .169 & .092 & -.049 & .265 \\
\hline Weather conditions & -.139 & 0.541 & .120 & .309 & .317 & .352 & .298 & .051 \\
\hline Frequency of working overtime & .151 & -.093 & 0.773 & .017 & .342 & -.096 & .155 & .082 \\
\hline Working at heights & .006 & .379 & 0.691 & .025 & -.012 & .302 & .266 & -.026 \\
\hline Working 7 days per week & .371 & .223 & 0.677 & .185 & .118 & -.098 & .090 & .173 \\
\hline Inadequate safety plan & .465 & .155 & 0.648 & .141 & .067 & .372 & -.026 & .090 \\
\hline Unrealistic scheduling & -.001 & -.012 & 0.496 & .426 & .217 & .334 & -.236 & .459 \\
\hline Lack of empowerment & .160 & .007 & -.131 & 0.812 & -.009 & .025 & -.067 & -.056 \\
\hline Poor or no supervision method & -.210 & .370 & .121 & 0.663 & .125 & -.319 & .041 & 127 \\
\hline Low labor morale/commitment & .129 & .078 & .128 & 0.655 & .179 & .185 & .217 & 177 \\
\hline $\begin{array}{l}\text { Poor relations between labor and } \\
\text { superintendents }\end{array}$ & .344 & .150 & .244 & 0.635 & -.024 & .099 & .146 & .059 \\
\hline High workforce absenteeism & -.018 & 139 & .212 & -.124 & 0.769 & .197 & .255 & .185 \\
\hline Incompetent supervisors & .386 & .325 & .166 & .218 & 0.647 & -.166 & -.077 & -.240 \\
\hline $\begin{array}{l}\text { Lack of skill and experience of the } \\
\text { workers }\end{array}$ & .209 & .062 & .133 & .402 & 0.622 & .117 & .238 & .282 \\
\hline Accidents & .335 & .056 & 136 & 212 & 0.518 & .393 & -.163 & 225 \\
\hline $\begin{array}{l}\text { Variations/Change Order During } \\
\text { Executions }\end{array}$ & .077 & .066 & .041 & .075 & .078 & 0.876 & .067 & .082 \\
\hline Unsafe working conditions & .404 & .271 & .370 & -.127 & .278 & 0.513 & .062 & .101 \\
\hline Little or no financial rewards & .084 & -.118 & .128 & .156 & .045 & .051 & 0.894 & .140 \\
\hline Low amount of pay & .524 & .028 & .231 & -.044 & .347 & .044 & 0.605 & .010 \\
\hline Lack of labor surveillance & .389 & .066 & .085 & .275 & .133 & .066 & .180 & 0.732 \\
\hline Payment Delay & .092 & .308 & .458 & -.104 & .228 & .147 & .319 & 0.592 \\
\hline
\end{tabular}


Table 6. Various LP factors reorganized in to new groups obtained from Factor Analysis.

\begin{tabular}{|c|l|c|l|}
\hline S. No & $\begin{array}{l}\text { Reorganized LP } \\
\text { Groups }\end{array}$ & Nos & Factors \\
\hline 1 & Work Delay & 4 & $\begin{array}{l}\text { Poor condition of tools and equipment, Bad Leadership skill, Rework and } \\
\text { Poor work planning }\end{array}$ \\
\hline 2 & $\begin{array}{l}\text { Work } \\
\text { Characteristics }\end{array}$ & 5 & $\begin{array}{l}\text { Method of construction, Equipment tools and shortages, Effectiveness of } \\
\text { management system, Material shortages and Weather conditions }\end{array}$ \\
\hline 3 & Work Schedule & 5 & $\begin{array}{l}\text { Frequency of working overtime, Working at heights, Working 7 days a } \\
\text { week, Inadequate safety plan and Unrealistic scheduling }\end{array}$ \\
\hline 5 & $\begin{array}{l}\text { Organizational } \\
\text { Characteristics }\end{array}$ & 4 & $\begin{array}{l}\text { Lack of empowerment, Poor or no supervision method, Low labour } \\
\text { morale and Poor relation between labour and superintendents }\end{array}$ \\
\hline 6 & $\begin{array}{l}\text { Sssured \& } \\
\text { Wofety work }\end{array}$ & 4 & $\begin{array}{l}\text { High workforce absenteeism, Incompetent supervisor, Lack of skill and } \\
\text { experience of the workers and Accidents }\end{array}$ \\
\hline 7 & Workers Income & 2 & $\begin{array}{l}\text { Variations/change order during execution and Unsafe working } \\
\text { conditions }\end{array}$ \\
\hline 8 & $\begin{array}{l}\text { Workers } \\
\text { Management }\end{array}$ & 2 & Lack of labour surveillance and Payment delay financial rewards and low amount of pay \\
\hline
\end{tabular}

Table 7. Cronbach's $\alpha$ of reorganized group of LP factors.

\begin{tabular}{|c|l|c|}
\hline S. No & \multicolumn{1}{|c|}{ Reorganized LP Groups } & Cronbach's $\boldsymbol{\alpha}$ \\
\hline 1 & Work Delay & 0.787 \\
\hline 2 & Work Characteristics & 0.787 \\
\hline 3 & Work Schedule & 0.820 \\
\hline 4 & Organizational Characteristics & 0.748 \\
\hline 5 & Assured and Safety Work & 0.654 \\
\hline 6 & Work Conditions & 0.617 \\
\hline 7 & Workers Income & 0.737 \\
\hline 8 & Workers Management & 0.761 \\
\hline
\end{tabular}

\subsection{Field Study}

The field study is carried out using TMS technique on AAC block wall construction in an ongoing construction of a five storied residential apartment. Activity (wall construction) is carried out in combination of two workers (mason and helper). Total twenty-four combinations have been recorded as observations. All the observations were taken at random days starting from mid-October to mid-December, 2017. Random timings were chosen such that the activity is in full progress with no external disturbances such as extreme weather conditions. Observations under productive and non-productive work are classified as shown in the Table 2. Quantity of constructed wall on field is calculated in square feet and time data is recorded for the involved labour task motions in minutes. Time observation trails were carried for at least 30 minutes per combination. Total time and work quantity from which workers were observed for the construction activity is 2021 minutes and 600 square feet respectively. LP is calculated in minutes per square feet.

The time data for both working and non-working time task motions are tabulated (see Table 1 in the appendix). To calculate the productive time spent on specified construction activity, time data is converted in to percentages from the total time of observation (see Table 2 in the appendix). Actual productivity of workers is only the percentage of time spent on productive tasks performed by the workers. Average percentage of time spent for productive and non-productive task motions are calculated (see Table 8). 
Table 8. Average percentage of time spent on various task motions of wall construction activity.

\begin{tabular}{|l|c|l|c|}
\hline $\begin{array}{l}\text { Productive task } \\
\text { motions }\end{array}$ & $\begin{array}{c}\text { Average time spent } \\
(\mathbf{\%})\end{array}$ & $\begin{array}{l}\text { Non-Productive task } \\
\text { motions }\end{array}$ & $\begin{array}{c}\text { Average time spent } \\
\mathbf{( \% )}\end{array}$ \\
\hline Brick Laying & 44 & Material Delay & 9 \\
\hline Alignment & 20 & Tools Delay & 2 \\
\hline Finishing & 13 & Supervision Delay & 3 \\
\hline Joinery Installation & 1 & Unskilled Work Delay & 1 \\
\hline Brick Slicing & 5 & Idle/Talking to others & 1 \\
\hline Scaffold Installation & 1 & Miscellaneous & 1 \\
\hline Total & 83 & Total & 17 \\
\hline
\end{tabular}

\section{Discussion}

From the TMS technique, it is observed that total $83 \%$ of productive time is spent by workers for productive task motions. Non-productive task motions such as idle/talking to others and miscellaneous may sometimes require for resting period against physical fatigue. The allowable rest period of the workers against basic physical fatigue is $4 \%$ as per International Labour Organization [28]. Thus, average time on effective nonproductive task motions is $15 \%$ which is an unnecessary time spent by workers. This is obtained by deducting the $2 \%$ observed from two task motions such as idle/talking to others and miscellaneous from overall $17 \%$ resulted on site observations. Even though the field study is carried out during the selected working days where no loss is expected, only $85 \%$ of productivity is achieved by the workers on the construction site.

The non-productive time is influenced by various LP factors in the construction. The data analysis of the survey resulted after regrouping of LP factors is given in Table 5. An observation from regrouping of LP factors shows that factors such as equipment tools and shortages, effectiveness of management system, material shortages and weather conditions fall under work characteristics. Of these factors, the equipment and tools shortages and material shortages have corresponding non-productive task motions in TMS observations on construction field and these task motions are tools delay and material delay. Thus, the correlation between LP factors and non-productive work task motions are shown in Table 9. Also, the percentage of influence is shown against each non-productive task motion. Similar correlations can be noticed between organization characteristics and supervision delay task motion; assured and safety work to unskilled work delay task motion; workers management to idle/talking to others task motion. Hence, there exists a correlation between LP factors and non-productive work task motions and TMS have quantified the influence on LP.

Table 9. LP factors correlated to non-productive work task motions observed from construction site.

\begin{tabular}{|l|l|c|}
\hline Reorganized LP Factors & Non-Productive Work Task Motions on Site & Influence (\%) \\
\hline \multirow{2}{*}{ Work Characteristics } & Tools Delay & 2 \\
\cline { 2 - 3 } & Material Delay & 9 \\
\hline Organizational Characteristics & Supervision Delay & 3 \\
\hline Assured and Safety Work & Unskilled Work Delay & 1 \\
\hline Workers Management & Idle/Talking to others & 2 \\
\hline
\end{tabular}

Measurement of LP is assessed at various levels such as company, field operations, project, activity, work processes and task in a construction organization [29]. LP factors resulted from the statistical analysis are linked to various levels of measuring LP in the construction projects. As the present case study focused on a single construction activity, $85 \%$ of LP is observed when LP factors at activity, work processes and task levels are covered in the field observation. This has not covered the LP factors at various higher levels such as company, filed operations and project in the construction organization.

From the present field study, it is observed that factors related to work characteristics plays a major role in influencing the LP on construction sites. Work characteristics determines the labour working process in handling the materials and tools. Tools delay is caused mainly due to sharing of measurement tools with co- 
workers such as plumb bob, measurement tape, spirit level etc., due to unavailability of sufficient tools on site. Material delay is the major factor influencing the LP on site and is caused due to unavailability of material at the time of work. The required amount of materials is transported from a distance away to work location in the same floor. Sometimes masonry worker himself carried the materials to the work spot which caused delay and physical fatigue. Therefore, workers/helpers are needed to be increased or guided properly to transport and handle the bricks to the work locations. Supervision delay and unskilled work delay are $3 \%$ and $1 \%$ respectively. But, these factors can also be managed from proper utilization of available resources on site.

This study surveyed the factors that are influencing the LP on construction projects in India. There was consensus concerning the factors that were considered to be important towards the LP. It is found that some of the LP influencing factors from questionnaire survey analysis also showing considerable effect in construction field study (see Table 7). From the case study, it is observed that non-productive labour tasks are related to the factors responsible for low LP (see Table 8). Work characteristics involving material shortages and tools delay is found to be most important factors influencing the LP. Therefore, factors from the questionnaire survey method showed the validation regarding the influence of LP on the construction site. By addressing the work characteristics factors that are causing the low construction LP in the field, site engineers can address the problems and minimize the time and cost overruns. Thus, the present study introduced an approach for quantitative validation of LP factors in India by correlating TMS (field work measurement) and SPSS (questionnaire survey analysis) data.

\section{Conclusions}

The entire scheme is carried out from the analysis of surveyed data using SPSS to the LP at field level obtained by carrying out TMS technique for a wall construction activity in a residential building construction site in TS, India. The results from the site observations indicated that the four out of eight group of LP factors obtained from the SPSS analysis were found influencing on the construction project site. These four factors were quantitatively assessed and linked to the LP measurement. Considering basic physical fatigue allowance, loss of LP on site due to work characteristics and assured and safety work is found to be $15 \%$ in the construction field. Material shortage and tools delay were found to be the most influencing LP factors in the project site. To overcome these problems, the management should always coordinate well with site engineers to provide sufficient tools and equipment and sufficient workers/helpers to handle the required materials at work locations. Likewise, engineers/managers in the construction projects can measure and manage the LP with minimum observation of worker's task motions on site.

By delving in to the study, the statistical analysis had revealed eight-groups of essential factors responsible for the loss of LP in construction projects in India which include: work delay; work characteristics; work schedule; organizational characteristics; assured and safety work; work conditions; workers income; workers management. Further research should be extended to the various other masonry activities in different types of construction projects in India. This approach can aid construction firms considering the crucial factors influencing loss of LP in productivity estimates at various levels in the construction organizations. Also, field validations in construction projects can be accurately assessed from the available research findings instead of burdensome daily progress reports of project data procurement. Altogether, the prime value of the study is that the correlation of TMS technique to the regression analysis can be used for quantitative validation of LP factors. It also provides a practical means of developing the LP in such a way that not only finding out essential factors but also quantifying them in real time construction projects.

Since the present study on LP factors were focused in India, filed observation in a specific location and with a particular activity, the findings constitute to create intrinsic challenges in generalization. However, the relationship between heuristic and filed data shown in the present study will aid industry people in taking timely decisions to improve the LP in the construction projects. The systematic methodology to assess the $\mathrm{LP}$ on construction projects sites in India provides scope for further based research aiming at other masonry construction activities in different locations. Besides, results from this study also directs to new routes for upcoming researchers in construction productivity studies and application.

\section{References}

[1] Investopedia. (2017). Labour Intensive. [Online]. Available: https://www.investopedia.com/terms/1/ laborintensive.asp [Accessed: 11 November 2017] 
[2] S. Ulubeyli, A. Kazaz, and B. Er, "Planning engineers' estimates on labor productivity: Theory and practice," Procedia-Social and Behavioral Sciences, no. 119, pp.12-19, 2014.

[3] K. W. Chui, D. R. Shields, and Y. Bai, "On-site labor productivity measurement for sustainable construction," in Proceedings of International Conference on Sustainable Design and Construction, ICSDC 2011Integrating Sustainability Practices in the Construction Industry, ASCE, Kansas City, Missouri, 2012, pp. 335343.

[4] S. Durdyev and J. Mbachu, "On-site labour productivity of New Zealand construction industry: Key constraints and improvement measures," AJCE. Australasian Journal of Construction Economics and Building, vol. 11, no. 3, pp. 18-33, 2011

[5] C. K. Nyando and J. A. M. Strasheim, "Assessing labour-based construction works management processes," Proceedings of the Institution of Civil Engineers - Management, Procurement and Law, vol. 164, no. 4, pp. 239-251, 2012.

[6] C. H. Oglesby, H. W. Parker, and G. A. Howell, Productivity Improvement in Construction. New York: McGraw Hill, 1989.

[7] S. Loganathan and S. Kalidindi, "Masonry labour construction productivity variation: An Indian case study," in Proceedings of the First Indian Lean Construction Conference, Mumbai, India, 2015, no. 1, pp.175185.

[8] K. M. Harmon and B. Cole, "Loss of productivity studies-Current uses and misuses," Construction Briefings, vol. 8, no. 1, pp. 1-19, 2006.

[9] S. E. Thomas, "Proving productivity losses in government contracts," Public Contract Law Journal., vol. 18, no. 2, pp. 414-431, 1989.

[10] M. R. A. Kadir, W. P. Lee, M .S. Jaafar, S. M. Sapuan, and A. A. A. Ali, "Factors affecting construction labour productivity for Malaysian residential projects," Structural Survey, vol. 23, no. 1, pp. 42-54, 2005.

[11] B. G. Hickson and L. A. Ellis, "Factors affecting construction labour productivity in Trinidad and Tobago," The Journal of the Association of Professional Engineers of Trinidad and Tobago, vol. 42, no. 1, pp. 4 11, 2014.

[12] A. M. Jarkas, R. A. Al Balushi, and P. K. Raveendranath, "Determinants of construction labour productivity in Oman," International Journal of Construction Management, vol. 15, no. 4, pp. 332-344, 2015.

[13] I. Mahamid, "Contractors perspective toward factors affecting labor productivity in building construction," Engineering, Construction and Architectural Management, vol. 20, no. 5, pp. 446-460, 2013

[14] S. Naoum and J. Hackman, "Do site managers and the head office perceive productivity factors differently?," Engineering, Construction and Architectural Management, vol. 3, no. 1, pp. 147-160, 1996.

[15] A. S. Hanna and D. G. Heale, "Factors affecting construction productivity: Newfoundland versus rest of Canada," Canadian Journal of Civil Engineering, vol. 21, no.4, pp. 663-673, 1994.

[16] H. R. Thomas, "Labor productivity and work sampling: The bottom line," Journal of Construction Engineering and Management, vol. 117, no. 3, pp. 423-444, 1991.

[17] C. P. Sing, P. E. D. Love, and C. M. Tam, "Multiplier model for forecasting manpower demand," Journal of Construction Engineering and Management, vol. 138, no. 10, pp. 1161-1168, 2012.

[18] J. M. W. Wong, A. P. C. Chan, and Y. H. Chiang, "A critical review of forecasting models to predict manpower demand," The Australian Journal of Construction Economics and Building, vol. 4, no. 2, pp. 43-55, 2004.

[19] N. Jokkaw, P. Suteecharuwat, and P. Weerawetwat, "Measurement of construction workers' feeling by virtual environment (VE) technology for guardrail design in high-rise building construction projects," Engineering Journal, vol. 21, no. 5, pp. 161-177, Sept. 2017.

[20] N. A. Sheikh, F. Ullah, B. Ayub, and M. J. Thaheem, "Labor productivity assessment using activity analysis on semi high-rise building projects in Pakistan," Engineering Journal, vol. 21, no. 4, pp. 273-286, Jul. 2017.

[21] Recommendations for Labour Output Constants for Building Works, Bureau of Indian Standards, India, IS (Indian Standard) IS 7272-1, 2006.

[22] H. R. Thomas and J. Daily, "Crew performance measurement via activity sampling," Journal of Construction Engineering and Management, vol. 109, no. 3, pp. 309-320, Sept. 1983.

[23] S. A. Finkler, J. R. Knickman, G. Hendrickson, M. Lipkin, Jr., and W. G. Thompson, "A comparison of work sampling and time-and-motion techniques for studies," Health Services Research, vol. 28, no. 5, pp. 577-597, 1993.

[24] E. M. Marvin and L. D. David, Motion and Time Study: Improving Productivity. London, UK: Pearson Publication, 1994. 
[25] A. T. Bon and D. Daim, "Time motion study in determination of time standard in manpower process," in Proceedings of 3rd Engineering Conference on Advancement in Mechanical and Manufacturing for Sustainable Environment, Kuching, Sarawak, Malaysia, 2010.

[26] J. F. Hair, W. C. Black, B. J. Babin ,and R. E. Anderson, Multivariate Data Analysis. New Jersey: Prentice Hall, 2009.

[27] M. Gunduz, Y. Nielsen, and M. Ozdemir, "Quantification of delay factors using the relative importance index method for construction projects in Turkey," Journal of Management in Engineering, ASCE, vol. 29, no. 2, pp. 133-139, 2013.

[28] G. Kanawaty, Introduction to Work Study, $4^{\text {th }}$ revised ed. International Labour Organization, 1992.

[29] E. M. Rojas, "Construction Productivity: A Practical Guide for Building and Electrical Contractors. Florida: J. Ross Publishing, 2008. 


\section{Appendix}

Table A1. Collection of working and non-working time data for various task motions from the field observations.

\begin{tabular}{|c|c|c|c|c|c|c|c|c|c|c|c|c|c|c|c|}
\hline Obs & Time & Qty & Prod. & \multicolumn{1}{|c|}{ Working time task motions } & \multicolumn{1}{|c|}{ Non-working time task motions } \\
\hline & (min) & (sft) & $(\mathrm{min} / \mathrm{sft})$ & BL & AL & FIN & JI & BS & SI & MD & TD & SD & LSD & UD & MISC \\
\hline 1 & 34 & 6 & 6 & 13 & 6 & 11 & 0 & 1 & 0 & 2 & 1 & 0 & 0 & 0 & 0 \\
\hline 2 & 111 & 37 & 3 & 51 & 24 & 2 & 0 & 9 & 1 & 15 & 0 & 4 & 0 & 0 & 5 \\
\hline 3 & 48 & 12 & 4 & 30 & 7 & 4 & 0 & 2 & 0 & 3 & 0 & 2 & 0 & 0 & 0 \\
\hline 4 & 70 & 11 & 6 & 34 & 9 & 12 & 0 & 6 & 0 & 6 & 0 & 0 & 0 & 3 & 0 \\
\hline 5 & 98 & 27 & 4 & 39 & 21 & 12 & 2 & 9 & 4 & 8 & 0 & 3 & 0 & 0 & 0 \\
\hline 6 & 56 & 17 & 3 & 30 & 12 & 0 & 0 & 0 & 0 & 5 & 3 & 0 & 6 & 0 & 0 \\
\hline 7 & 32 & 8 & 4 & 10 & 5 & 0 & 0 & 3 & 1 & 2 & 1 & 7 & 1 & 2 & 0 \\
\hline 8 & 51 & 15 & 3 & 24 & 12 & 12 & 0 & 1 & 0 & 0 & 0 & 0 & 0 & 0 & 2 \\
\hline 9 & 111 & 24 & 5 & 43 & 10 & 14 & 1 & 7 & 0 & 23 & 4 & 5 & 0 & 2 & 2 \\
\hline 10 & 158 & 45 & 4 & 73 & 27 & 27 & 0 & 8 & 3 & 9 & 3 & 4 & 2 & 0 & 2 \\
\hline 11 & 30 & 11 & 3 & 14 & 2 & 4 & 0 & 0 & 0 & 10 & 0 & 0 & 0 & 0 & 0 \\
\hline 12 & 130 & 51 & 3 & 72 & 23 & 9 & 0 & 9 & 0 & 9 & 3 & 5 & 0 & 0 & 0 \\
\hline 13 & 73 & 29 & 3 & 40 & 18 & 0 & 1 & 7 & 0 & 1 & 0 & 5 & 1 & 0 & 0 \\
\hline 14 & 244 & 48 & 5 & 78 & 25 & 30 & 0 & 62 & 2 & 24 & 2 & 14 & 6 & 0 & 1 \\
\hline 15 & 163 & 38 & 4 & 76 & 32 & 9 & 0 & 7 & 3 & 15 & 5 & 12 & 0 & 4 & 0 \\
\hline 16 & 58 & 30 & 2 & 36 & 18 & 0 & 0 & 0 & 0 & 4 & 0 & 0 & 0 & 0 & 0 \\
\hline 17 & 51 & 33 & 2 & 27 & 17 & 0 & 0 & 3 & 0 & 1 & 3 & 0 & 0 & 0 & 0 \\
\hline 18 & 114 & 32 & 4 & 71 & 7 & 16 & 0 & 3 & 3 & 9 & 0 & 5 & 0 & 0 & 0 \\
\hline 19 & 61 & 20 & 3 & 14 & 22 & 0 & 6 & 1 & 0 & 16 & 0 & 0 & 0 & 0 & 2 \\
\hline 20 & 50 & 22 & 2 & 14 & 12 & 13 & 1 & 3 & 0 & 2 & 1 & 4 & 0 & 0 & 0 \\
\hline 21 & 63 & 34 & 2 & 32 & 12 & 6 & 0 & 3 & 0 & 5 & 0 & 5 & 0 & 0 & 0 \\
\hline 22 & 47 & 6 & 8 & 3 & 3 & 27 & 0 & 1 & 0 & 9 & 1 & 0 & 0 & 0 & 3 \\
\hline 23 & 97 & 37 & 3 & 42 & 27 & 20 & 0 & 3 & 0 & 0 & 3 & 0 & 0 & 1 & 1 \\
\hline 24 & 71 & 7 & 10 & 28 & 22 & 16 & 0 & 0 & 0 & 4 & 1 & 0 & 0 & 0 & 0 \\
\hline
\end{tabular}


Table A2. Conversion of time data on various task motions into percentage of work performed.

\begin{tabular}{|c|c|c|c|c|c|c|c|c|c|c|c|c|c|c|c|}
\hline Obs & Time & Qty & Prod. & \multicolumn{6}{|c|}{ Working time task motions } & \multicolumn{6}{|c|}{ Non-working time task motions } \\
\hline & $(\min )$ & $(\mathrm{sft})$ & $(\mathrm{min} / \mathrm{sft})$ & $\mathrm{BL}$ & $\mathrm{AL}$ & FIN & $\mathrm{JI}$ & $\mathrm{BS}$ & SI & $\mathrm{MD}$ & TD & $\mathrm{SD}$ & LSD & $\mathrm{UD}$ & MISC \\
\hline 1 & 100 & 6 & 17 & 38 & 18 & 32 & 0 & 3 & 0 & 6 & 3 & 0 & 0 & 0 & 0 \\
\hline 2 & 100 & 37 & 3 & 46 & 22 & 2 & 0 & 8 & 1 & 14 & 0 & 4 & 0 & 0 & 5 \\
\hline 3 & 100 & 12 & 8 & 63 & 15 & 8 & 0 & 4 & 0 & 6 & 0 & 4 & 0 & 0 & 0 \\
\hline 4 & 100 & 11 & 9 & 49 & 13 & 17 & 0 & 9 & 0 & 9 & 0 & 0 & 0 & 4 & 0 \\
\hline 5 & 100 & 27 & 4 & 40 & 21 & 12 & 2 & 9 & 4 & 8 & 0 & 3 & 0 & 0 & 0 \\
\hline 6 & 100 & 17 & 6 & 54 & 21 & 0 & 0 & 0 & 0 & 9 & 5 & 0 & 11 & 0 & 0 \\
\hline 7 & 100 & 8 & 13 & 31 & 16 & 0 & 0 & 9 & 3 & 6 & 3 & 22 & 3 & 6 & 0 \\
\hline 8 & 100 & 15 & 7 & 47 & 24 & 24 & 0 & 2 & 0 & 0 & 0 & 0 & 0 & 0 & 4 \\
\hline 9 & 100 & 24 & 4 & 39 & 9 & 13 & 1 & 6 & 0 & 21 & 4 & 5 & 0 & 2 & 2 \\
\hline 10 & 100 & 45 & 2 & 46 & 17 & 17 & 0 & 5 & 2 & 6 & 2 & 3 & 1 & 0 & 1 \\
\hline 11 & 100 & 11 & 9 & 47 & 7 & 13 & 0 & 0 & 0 & 33 & 0 & 0 & 0 & 0 & 0 \\
\hline 12 & 100 & 51 & 2 & 55 & 18 & 7 & 0 & 7 & 0 & 7 & 2 & 4 & 0 & 0 & 0 \\
\hline 13 & 100 & 29 & 3 & 55 & 25 & 0 & 1 & 10 & 0 & 1 & 0 & 7 & 1 & 0 & 0 \\
\hline 14 & 100 & 48 & 2 & 32 & 10 & 12 & 0 & 25 & 1 & 10 & 1 & 6 & 2 & 0 & 0 \\
\hline 15 & 100 & 38 & 3 & 47 & 20 & 6 & 0 & 4 & 2 & 9 & 3 & 7 & 0 & 2 & 0 \\
\hline 16 & 100 & 30 & 3 & 62 & 31 & 0 & 0 & 0 & 0 & 7 & 0 & 0 & 0 & 0 & 0 \\
\hline 17 & 100 & 33 & 3 & 53 & 33 & 0 & 0 & 6 & 0 & 2 & 6 & 0 & 0 & 0 & 0 \\
\hline 18 & 100 & 32 & 3 & 62 & 6 & 14 & 0 & 3 & 3 & 8 & 0 & 4 & 0 & 0 & 0 \\
\hline 19 & 100 & 20 & 5 & 23 & 36 & 0 & 10 & 2 & 0 & 26 & 0 & 0 & 0 & 0 & 3 \\
\hline 20 & 100 & 22 & 5 & 28 & 24 & 26 & 2 & 6 & 0 & 4 & 2 & 8 & 0 & 0 & 0 \\
\hline 21 & 100 & 34 & 3 & 51 & 19 & 10 & 0 & 5 & 0 & 8 & 0 & 8 & 0 & 0 & 0 \\
\hline 22 & 100 & 6 & 17 & 6 & 6 & 57 & 0 & 2 & 0 & 19 & 2 & 0 & 0 & 0 & 6 \\
\hline 23 & 100 & 37 & 3 & 43 & 28 & 21 & 0 & 3 & 0 & 0 & 3 & 0 & 0 & 1 & 1 \\
\hline 24 & 100 & 7 & 14 & 39 & 31 & 23 & 0 & 0 & 0 & 6 & 1 & 0 & 0 & 0 & 0 \\
\hline & & & Average & 44 & 20 & 13 & 1 & 5 & 1 & 9 & 2 & 3 & 1 & 1 & 1 \\
\hline
\end{tabular}

